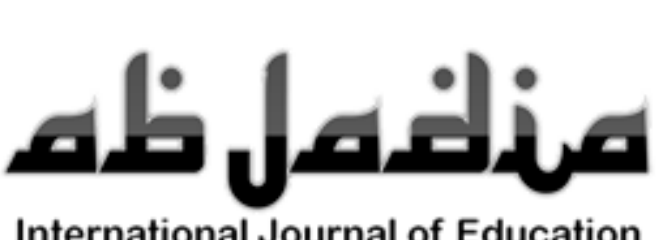

International Journal of Education

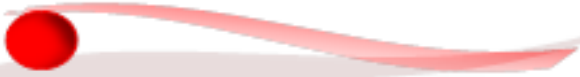

Pi] Publisher

Fakultas Ilmu Tarbiyah dan Keguruan Universitas Islam Negeri (UIN) Mualana Malik Ibrahim Malang Indonesia

- 2443-0587 - ISSN Online

尚 2528-3979 - ISSN Print

傮 History Article

t) Received : 15-10-2017

(13) Reviced : 02-11-2017

目 Accepted : 29-12-2017

\section{doi.org/ 10.18860/abj..v2i2.5363}

http://ejournal.uin-malang.ac.id/index.php/ abjadia/article/view/5363

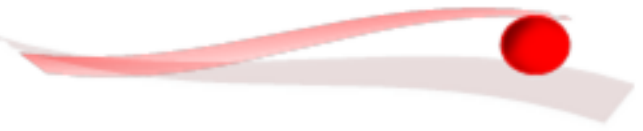

Q Nur Aini Majidah

9. Indonesia

? Universitas Islam Negeri

Maulana Malik Ibrahim

Malang Indonesia

\section{Corresponding Author}

(C) 085646418673

@ nourainimajidah@gmail.com

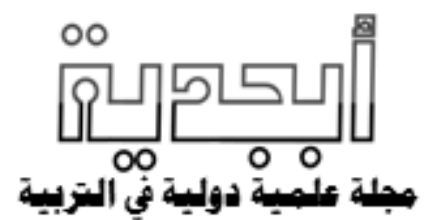

Nur Aini Majidah

Indonesia

$$
\text { المستخدام لعبة المونوبولي في ترقية كفاءة }
$$

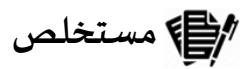

إ المفردات هي واحدة من العناصر الهامة للغة. يتطلب تعلم المفردات

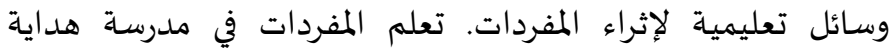

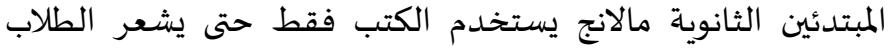

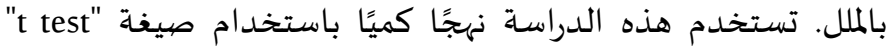

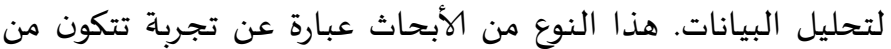

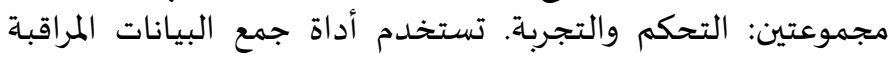

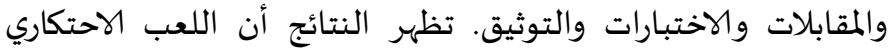

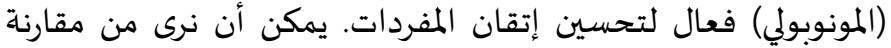

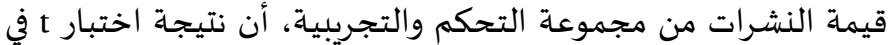
هذه الدراسة (2.68) ، من أكبر من قيمة اختبار t عند مستوى 1. (2.42) و ج) الوسيلة التعليمية، لعبة المونوبولي، تعليم المفردات

\section{㩑" Abstract}

Vocabulary is one of the important elements of language. Vocabulary learning requires learning media to enrich vocabulary. Vocabulary learning in MTs Hidayatul Mubtadi'in Malang only uses books so students feel bored. This study uses a quantitative approach using the formula "t test" to analyze the data. This type of research is an experiment consisting of two groups: control and experiment. The data collection instrument uses observation, interviews, tests and documentation. The results show that monopoly play is effective for improving vocabulary mastery. It can be seen from the comparison of postes value from the control and experimental group, that the result of $t$ test in this study (4.29), is greater than the value of $t$ test at the level of $1 \%(2.42)$ and $5 \%(2.68)$.

@ Learning Media, Monopoly Games, Vocabulary Learning 


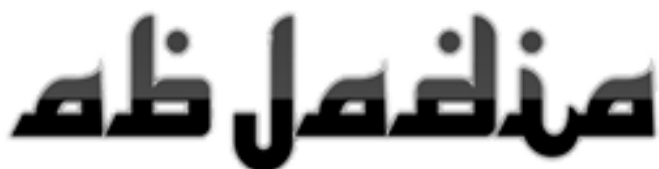

International Journal of Education

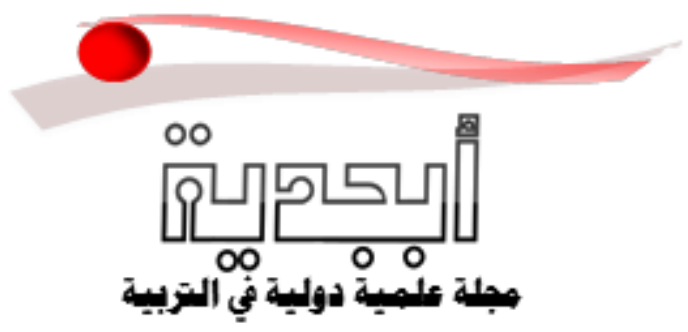

\section{留, Abstrak}

Kosakata merupakan salah satu dari unsur bahasa yang penting. Pembelajaran kosakata membutuhkan media pembelajaran untuk memperkaya kosakata. Pembelajaran kosakata di MTs Hidayatul Mubtadi'in Malang hanya menggunakan buku sehingga siswa merasa jenuh. Penelitian ini menggunakan pendekatan kuantitatif dengan menggunakan rumus "uji $\mathrm{t}$ " untuk menganalisis datanya. Jenis penelitian ini adalah eksperimen yang terdiri dari dua kelompok: kontrol dan eksperimen. Instrumen pengumpulan datanya menggunakan observasi, wawancara, tes dan dokumentasi. Hasil penelitian menunjukkan bahwa permainan monopoli efektif untuk meningkatkan penguasaan kosakata. Hal ini dapat dilihat dari hasil perbandingan nilai postes dari kelompok kontrol dan eksperimen, bahwa hasil uji $t$ dalam penelitian ini $(4,29)$, lebih besar dari nilai uji t pada level $1 \%(2,42)$ dan $5 \%(2,68)$.

\section{@. Media Pembelajaran, Permainan Monopoli,} Pembelajaran Kosakata

http:// $\quad$ http://ejournal.uin-malang.ac.id/index.php/abjadia/article/view/5363

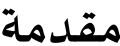

قال فرجوسون في مقال نشره بدائرة المعارف البريطانية "أن اللغة العربية سواء بالنسبة إلى عدد

الناطقين بها أو إلى مدى تأثيرها تعتبر إلى حد بعيد أعظم اللغات السـامية جمعاء. كما ينبغي أن ينظر إليها كإحدى اللغات العظمي في العالم اليوم" (طعيمة 1982).

إن اللغة العربية تتكون من أربع المهارات اللغوية وهي الاتماع والكلام والقراءة والكتابة، وتتكون أيضا من ثلاثة عناصر وهي الأصوات والتراكيب والمفردات. والمفردات عنصر من عناصر اللغة الهامة بحيث تتضمن عليها المعاني واستخدام الكلمات في اللغة من المتكلم نفسـه أو من الكاتب. والشخص ستزيد لله مهارته في اللغة إذا ازدادت مفرداته لأن كفاءة المهارة لغة الشخص متوفق على المفردات التي استوعب

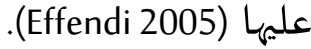

وقال أحمدفؤاد إيفيندي إن السبب الرئيسي لضعف المهارات لدي التلاميذ ربما يرجع إلى إتقانهم

على المفردات وطرق تدردسها و وسيلتها(Effendi 2005). وفي العصيور الحديثة اللغة العربية هي لغة التعليم ومادته في المدارس والمعاهد والجامعات. إن التلاميذ يتعلمون اللغة العربية يجب عليهم أن يعرفوا المفردات (Hamid and dkk 2008). يقرر دور المدرس عملية تعليم المفردات في الفصل. إذا أمر المدرس الطلاب أن يحفظوا المفردات فقط فيحمل الطلاب بكثرة الحفظ. فيحتاج إلى استخدام الوسيلة 
لعبة المونوبولي هي اللعبة المشهور لها أهداف للتسلّط. ويختلف المونوبولي كوسيلة باللعبة الأصلية. في هذه لوحة المونوبولي جميع المريع المصور وفيها الأسئلة تشـابة طريقة استخدامها باللعبة الأصلية. يجب على اللاعبين رمي النرد ويحرك البيذق إلى المربع المناسبة على رقم النرد، ثم يجيب الطلاب الأسئلة في ذلك المربع. إذا لم يكن كذلك يقول الطلاب الكلمة "يكفي" وتنتظر العقبة التالية. والطلاب يحصلون أكثر الفلوس هو الفائزة. أما لعبة المونوبولي في تعليم المفردات صممتها الباحثة نفسها لترقية كفاءة لترقية الرغبة والحماسـة في تعليم المفردات.

هذا البحث في مدرسة هداية المبتدئين المتوسطة الإسلامية بمالانج لأن هناك تستخدم تعليم اللغة العربية بالكتاب والمدرس فقط، لذا يشعر الطلاب الملل وقليل الرغبة ليتعلموا اللغة العربية. يعلم المدرس اللغة العربية بقراءة النص من الكتاب ثم يسأل التلاميذ عن المقروء. وأحيانا يعطي الوظيفة إلي التلاميذ للتقويم اليومي. ثم آخذت هذا البحث في الفصل الواحد لأنهم يحتاجون إلى تعريف المفردات وتفهيمها كي يسهلون لتعليم أربع مهارات.

بناء على خلفياة البحث تكون أسئلة البحث كما يلي: (1) كيف استخدام لعبة المونوبولي؟ (2) وما مدى فعالية استخدام لعبة المونوبولي في ترقية كفاءة المفردات بمدرسة هداية المبتدئين المتوسطة الإسلامياة بمالانج

\section{منهج}

إن منهج البحث هو المنهج التجريبي، وهو دراسـة موضوعية بنظام وبمراقبة جيدة لتنبؤ ومرابقبة حالة ظاهرة (Syamsuddin and Damianti 2006). وفي هذا المنهج استخدمت الباحثة لعبة المونوبولي في تعليم المفردات. أرادت الباحثة معرفة ما تغير في التجربة أو فعاليتها في التعليم. مدخل هذا البحث كمي. وهو مدخل يستخدم الأرقام يبدأ من جمع البيانات وتفسير إلى بيانات وتقديم من الحاصلات(Sugiyono 2011). و في هذا البحث متغيران، هو المتغير المستقل (المجموعة التجريبية) والمتغيرة التابع (المجموعاة الظابطة)، يحتاج المجموعاة لمقارنة بينهما، هل استخدام الجديدة مئثرة أو لا (Emzir 2009). مجتمع البحث جميع الأفراد أو الأشخاص لتعميم حصول البحث. إذا أرادت الملاحظة جمع عناصر في ولاية الملاحظة فيسمى بملاحظة المجتمع(Arikunto 2010). ومجتمع البحث طبلب في الفصل الواحد بمدرسـة هداية المبتدئين المتوسطة الإسلامية بمالانج. وعدده 81 تلميذا وكل الفصل 26 تلميذا. اختارت الباحثة التلاميذ في الفصل الواحد لأنهم يحتاجون إلى تعريف المفردات وتفهيمها كي يسهلون لتعليم أربع 
مهارات. وعينة في هذا البحث هو جميع الطلاب في الفصل الواحد أ و ج عن طريقة غارض المعينة (purpose sampling) (Sugiyono 2011). طريقة غارض المعينة هي طريقة تعيين بالحساب المعينة). الواحد (أ) كمجموعة التجريبية و الفصل الواحد (ج) كمجموعة الظابطة

طريقة جمع البيانات: (1) الملاحظة وهي جمع البياناتباستخدام العيون مباشرة دون الآلات الأخرى؛ (2) المقابلة هي عملية لنيل البيانات بطريقة المقابلة بين المقابِل و المقابَل بالآلة تسهى بإرشاد المقابلة (Emzir 2009)؛ (3) الاختبار هو من إحدى طرائق من جمع البيانات لنيل البيانات عن كفاءة الطلاب في أربعة مهارات اللغة وعناصرها؛ (4) الوثيقة وهي طريقة البحث لطلب الحقائق والبيانات من الوثائق والكتب والمجالات والرسائل والمذكورات وغيرها من المواد المكتوبة.

هذه البيانات يمكن أن تكون مفيدة للباحثة لدراسة وتفسير وحتى لتنبؤ استجابة للقضايا المحورية للبحوث. وثائق في البحوث والدراسات، ويستطيع الباحثة تحديد وجمع بيانات النص أو الصورة. كي تحصل الباحثة على البيانات الصيادقة، تحتاج الباحثة إلى أسلوب تحليل البيانات. فأسلوب الحسب لتحليل البيانات من البحث التجريبي هو بالرموز "t-test" . وهو ما يلي(Arikunto 2010):

$$
t=\frac{M x-M y}{\sqrt{\left(\frac{\sum x^{2}+\sum y^{2}}{N x+N y-2}\right)\left(\frac{1}{N x}+\frac{1}{N y}\right)}}
$$

\section{نتائج}

مدرسة هداية المبتدئين المتوسطة الإسلامية مالانج هي إحدى المدارس التابعة لمعهد هداية المبتدئين السلفي العصري بتاسيكمادو بمالانج. يقع هذا المعهد في شارع كياهي الحاج يوسف رقم 1 بقرية تاسيكمادو بمالانج جاوى الشرقية. ويبعد عن مدينة مالانج حوالي 566 كيلومتر في الاتجاه الشمالي، وتبلغ مساحتاه حوالي 3280 كمُ2. أسّس الشيخ الحاج أغوس سالم محفوظ يوسف معهد هداية المبتدئين في السنة 1972 م، وفي بداية تأسيسها درس فيه تسعة طلاب وسكنوا في بيته البسيط، ثم تطوّر هذا المعهد بجههده تطوّرا سريعا. وفي السنة 1989 م أسّس الشيخ الحاج أغوس سالم محفوظ يوسف مؤسسة هداية المبتدئين للتعليم 
الأدوات للعبة المونوبولي هي: (1) البيذق لينوب اللاعب؛ (2) النردان، وكل النرد له ستة وجوه؛ (3)

لوحة اللعبة؛ (4) فلوس اللعبة؛ (5) بطاقة سؤال أ و ب؛ (6) المواد الدراسي. استخدمت المبات الباحثة المواد الدراسي للفصل الواحد تحت الموضوع البيتي يعني المفردات في كتاب التعليميهم.

غرفة المكتب - غرفة الأكل - غرفة النوم - غرفة المذاكرة - غرفة الجلوس - الحمام - مصلى

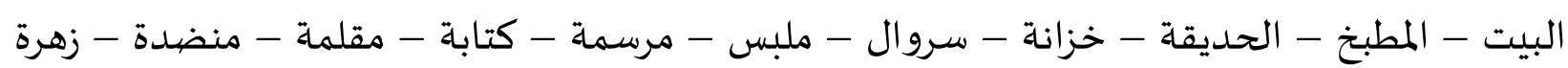
- زهرية - رز - شاي- ملعقة - سرير - وسادة - تقويم - صورة - ساعة - مصباح - قلم - تلفون - فاكس - مكتب - كرسي - رف - تلفزيون - شرفة - سور - شجرة - قهوة - مائدة - صحن بركة - مرحاض - مغرفة - صابون - ماء

تصيميم لوحة لعبة المونوبولي

اللعبة المونوبوليأن يصنع باستخدام الحاسوب يعني باستخدام البرنامج المشهور مايكورسوفت ورت

(Microsoft Word) فوتوشوب (Photoshop) أو غير ذلك. تحدد المفردات التي تصنع في هذه اللوحة يعنى المادة عن بيت. خطوات التصميم: (1) فتح برنامج مايكورسوفت ورت (Microsoft Word) في الحاسوب؛ (2) تغيير تخطيط

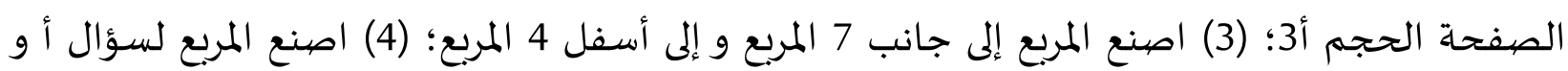

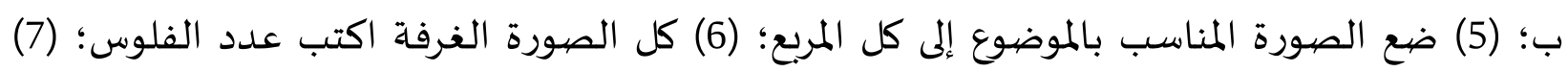
اعطي الصيورة التبدل في المربع.

الصورة (1) لوحة لعبة المونوبولي (Monopoli)

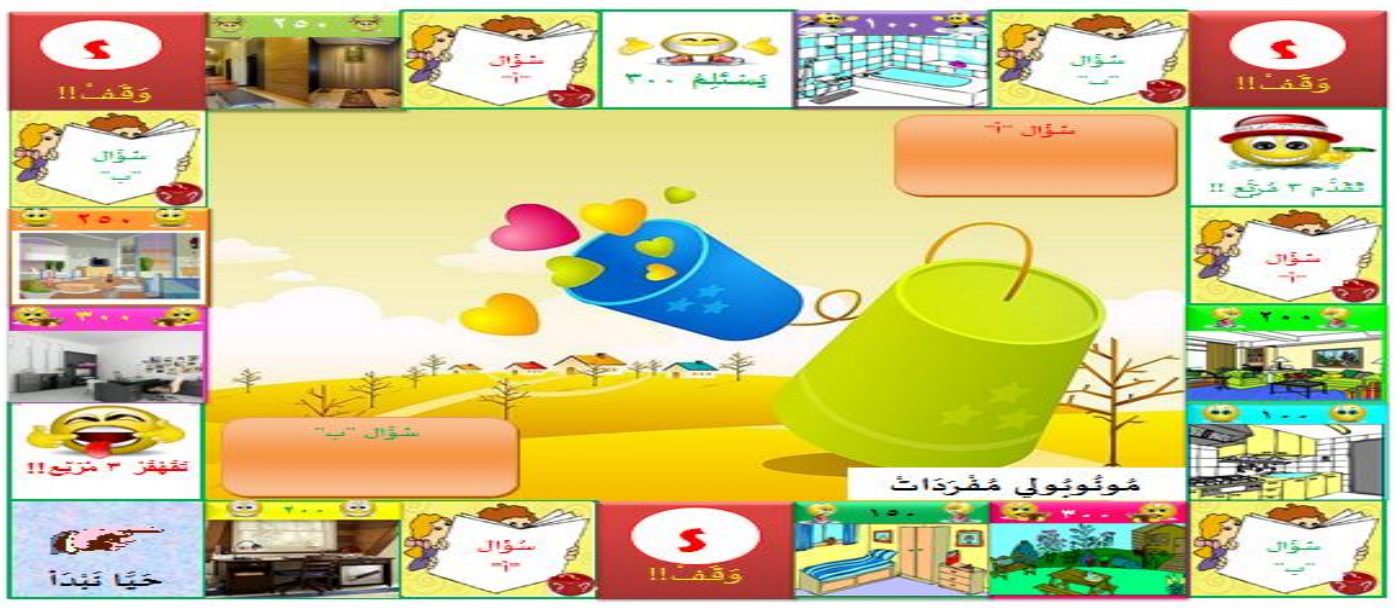




\section{نظام لعبة المونوبولي (Monopoli)}

نظام لعبة المونوبولي: (1) تقسم التلاميذ إلى الفرقات (وفقت تعداد التلاميذ في الفصل)؛ (2) يعطي لوحة اللعبة المونوبولي (Monopoli) والفلوس والبيذق والنرد إلى كل الفرقة؛ (3) يرمي النرد من كل الفرقة؛ (4) يتحرك البيذق حسبما الرقم المكتوب في النرد؛ (5) تجب على التلاميذ أن تجيب الأسئلة في كل الخانة؛ (6) إذا لا تستطيع التلاميذ أن تجيب الأسئلة تقول التلاميذ الكلمة "يكفي" وتنتظر العقبة التالية؛ (7) والتلاميذ يحصلون أكثر الفلوس هو الفائزة.

\section{تطبيق استخدام لعبة المونوبولي في تعليم المفردات}

عقدت الباحثة الملاحظة في المدرسة هداية المبتدئين المتوسطة الإسلامية بمالانج، والمقابلة مع رئيس المدرسة في الإدارة المدرسة هداية المبتدئين المتوسطة الإسلامية بمالانج، وحصلت الباحثة من هذه المقابلة هي تطوير هذه المدرسة. ونوع من أنواع تستخدم وسيلة التعليمية في الفصل. وطريقة المدرس في عملية التعليم والتعلّم. نتيجة التي قد يجد التلاميذ في المسابقة أيضا.

عقدت الباحثة المقابلة مع مدرّسة اللغة العببية في الإدارة المدرسين، وحصلت الباحثة من هذه المقابلة هي طريقة المستخدمة في تعليم المفردات هي بالطريقة المباشرة، ولكن لا تجد الباحثة استخدام اللعبة المونوبولي في هذه المدرسة. وهناك مشكلات بعض التلميذ من التلاميذ في تعليم المفردات، وعدد التلاميذ في فصل تجريبية 26 تلميذا وفصل ضابطة 26 تلميذا.

في اللقاء الأول، قامت الباحثة بالاختبار القبلي في المجموعة التجريبية. وقامت الباحثة بالاختبار القبلي في المجموعة الضابطة. فتحت الباحثة التعليم بالسلام وتقرأ البسملة وسألت الباحثة الحالة، التعارف ثم سألت عن المادة التي علّمت في الفصل مع مدرسهم، ثم أعطت الباحثة السؤال وأمر التلاميذ أن يفعلوا الإختبار. انتظرت الباحثة حتى انهاء الوقت، وختمت اللقاء بالسلام وقراءة الحمدلة. في اللقاء الثاني، قامت الباحثة بتطبيق اللعبة المونوبولي في المجموعة التجريبية، وأنشطة في الفصل كما يلي: (1) ابدأت الباحثة بالسلام والبسملة وسألت الحالة، ثم قرأت الباحثة كشف الحضور وسألت الباحثة من المفردات عن المادة التي قد تعليم من المدرّسة؛ (2) قبل تبدأ الدراسة قسمت الباحثة إلى مجموعين؛ (3) وأمرت الباحثة رئيس المجموعة ليأخذ اللعبة المونوبولي؛ (4) شرحت الباحثة من نظام لعبة المونوبولي؛ (5) تبدأ اللعبة, وشارفت الباحثة اللعبة؛ (6) عندما اللعبة، هنا لا يستطيع بعض التلاميذ أن يجيب المفردات عن البيت، ثم أمرت الباحثة أن ينظر إلى الكتاب؛ (7) وقبل اختتام في حصة 
5 دقائق، لخصت الباحثة عن اللعبة بالسؤال ويجيب التلاميذ في كل المجموعة؛؛ (8) وختمت الباحثة الدراسة بالسلام وقراءة الحمدلة.

في اللقاء الثالث، هناك المشكلات هي لا يستطيع التلاميذ أن يجبب المفردات، هم يشعرون صعوبة لأنهم نسيان المفردات. ثم قامت الباحثة بتطبيق اللعبة المونوبولي في المجموعة التجريبية كفي اللقاء الثاني وهم يستطعون أن يجيبون المفردات و هم يشعر مسرور جدّا باللعبة المونوبولي بالمادة التعليمية عن

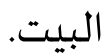

في اللقاء الرابع، قامت تفعل الباحثة بالإختبار البعدي في المجموعة الضابطة وفي المجموعاة

التجريبية.

\section{تقويم استخدام لعبة المونوبوليفي تعليم المفردات}

قامت الباحثة في هذا التقويم باستخدام الاختبار القبلى و الاختبار البعدي. الاختبار القبلي يعني اختبار يعطي قبل إجراء التجريبية للفصل التجريبي والظابط، والختبار البعدي يعني اختبار يعطي بعد إجراء التجريبية بعد استخدامت الباحثة اللعبة المونوبولي في تعليم المفردات أما في فصل الظابط بدون استخدام الباحثة اللعبة المونوبولي في تعليم المفردات.

\section{فُبْنَ مناقشَة}

فعالية استخدام لعبة المونوبولي في تعليم المفردات

نتائج الإختبار القيلي والبعلدي للمجمموعة الضابطة

\begin{tabular}{|c|c|c|c|}
\hline التقدير & الاختبار القبلي & اسـماء التلاميذ & الرقم \\
\hline جيد & 76 & أدي فراستيو & 1 \\
\hline ضعيف & 56 & أحمد زيزال مونتلا & 2 \\
\hline ضعيف & 56 & دفترا أناندا ساتيا ب & 3 \\
\hline مقبول & 60 & ديفا عفيفة زهرة & 4 \\
\hline ضعيف & 44 & فبري ألديانشا & 5 \\
\hline ضيعيف & 44 & فيرزام دار الفاناني & 6 \\
\hline جيد & 76 & جي فيفي فوتري أيوني & 7 \\
\hline جيد & 72 & لينا فورناما دوي & 8 \\
\hline ضعيف & 48 & منبع الهمة أ & 9 \\
\hline ضبعيف & 42 & ميغا فراستيوي & 10 \\
\hline ضعيف & 44 & ميشا عفيفة رحمة & 11 \\
\hline ضعيف & 56 & محمد فابيو جانافارو & 12 \\
\hline ضعيف & 56 & محمد أرجون سوريانشا & 13 \\
\hline ضعيف & 42 & محمدفخراني & 14 \\
\hline
\end{tabular}




\begin{tabular}{|c|c|c|c|}
\hline ضيعيف & 56 & محمد فيدي ي ف & 15 \\
\hline مقبول & 68 & نيها فربهاتين & 16 \\
\hline ضيعيف & 52 & نوفا أندرياني & 17 \\
\hline مقبول & 60 & نور السنتـا أ & 18 \\
\hline ضيعيف & 44 & ريدا يوليا تريسناواتي & 19 \\
\hline مقبول & 60 & رسما أدي ف & 20 \\
\hline مقبول & 60 & رسفاندي أغوس ك & 21 \\
\hline ضيعيف & 48 & رزكي فورنومو & 22 \\
\hline ضعيف & 44 & سافيرا إيكا أ & 23 \\
\hline ضعيف & 44 & سفتيان دوي فرناما فوترا & 24 \\
\hline مقبول & 60 & سيلفيا أ & 25 \\
\hline مقبول & 68 & فانيا ليل رمضياني & 26 \\
\hline & & 1436 & العدد ال العد \\
\hline & & 55,23 & المعدل \\
\hline
\end{tabular}

نتائج الاختبار القبلي للمجموعة الضبابطة

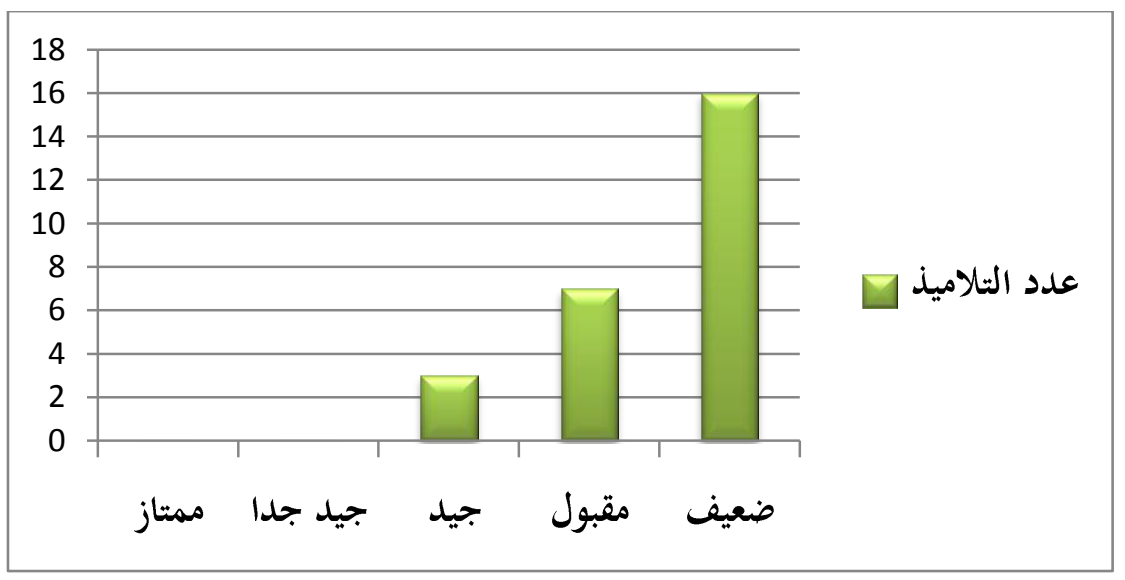

فمن نتائج هذا الاختبار القبلي, ظهر أن التلاميذ نالوا الدرجة المعدلة 55,23 وأما التلاميذ في مستوى ممتاز = 0 وفي مستوى جيد جدا = 0 وفي مستوى جيد = 3 وفي مستوى مقبول = 7 وفي مستوى ضيعيف = 16 و من هنا فإن قدرتهم على تعليم المفردات بصفة ضعيفة. نتائج الاختبار البعلدي للمجبموعة الضبابطة

\begin{tabular}{|c|c|c|c|}
\hline التقدير & الاختبار البعدي & اسماء التلاميذ & الرقم \\
\hline 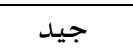 & 76 & | أدي فراستيو & 1 \\
\hline جيد & 76 & أحمد زبزال مونتلا & 2 \\
\hline جيد & 76 & دفترا أناندا ساتيا ب & 3 \\
\hline 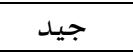 & 76 & ديفا عفيفة زهرة & 4 \\
\hline جيدجدا & 84 & فبري ألديانشا & 5 \\
\hline ضعيف & 56 & فيرزام دار الفاناني & 6 \\
\hline جيدجدا & 88 & جي فيفي فوتري أيوني & 7 \\
\hline 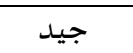 & 76 & لينا فورناما دوي & 8 \\
\hline مقبول & 60 & منبع الهمة أ & 9 \\
\hline مقبول & 60 & ميغا فراستيوي & 10 \\
\hline مقبول & 60 & ميشـا عفيفة رحمة & 11 \\
\hline
\end{tabular}




\begin{tabular}{|c|c|c|c|}
\hline 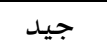 & 72 & محمد فابيو جانافارو & 12 \\
\hline مقبول & 60 & محمد أرجون سوريانشا & 13 \\
\hline ضعيف & 44 & محمدفخراني & 14 \\
\hline مقبول & 68 & محمد فيدي ي ف & 15 \\
\hline مقبول & 68 & نيها فريهاتين & 16 \\
\hline مقبول & 66 & نوفا أندرياني & 17 \\
\hline مقبول & 68 & نور السنتا أ & 18 \\
\hline ضعيف & 56 & ريدا يوليا تريسناواتي & 19 \\
\hline مقبول & 60 & رسما أدي ف & 20 \\
\hline جيد & 76 & رسفاندي أغوس ك & 21 \\
\hline ضعيف & 56 & رزكي فورنومو & 22 \\
\hline ضعيف & 56 & ساف يرا إيكا أ & 23 \\
\hline ضيف & 52 & سفتيان دوي فرناما فوترا & 24 \\
\hline مقبول & 60 & سيلفيا أ & 25 \\
\hline مقبول & 68 & فانيا ليل رمضاني & 26 \\
\hline \multicolumn{2}{|c|}{1718} & \multicolumn{2}{|l|}{ العدد } \\
\hline \multicolumn{2}{|c|}{66,07} & \multicolumn{2}{|l|}{ المعدل } \\
\hline
\end{tabular}

\section{نتائج الاختبار البعلدي للمتجموعة الضيابطة}

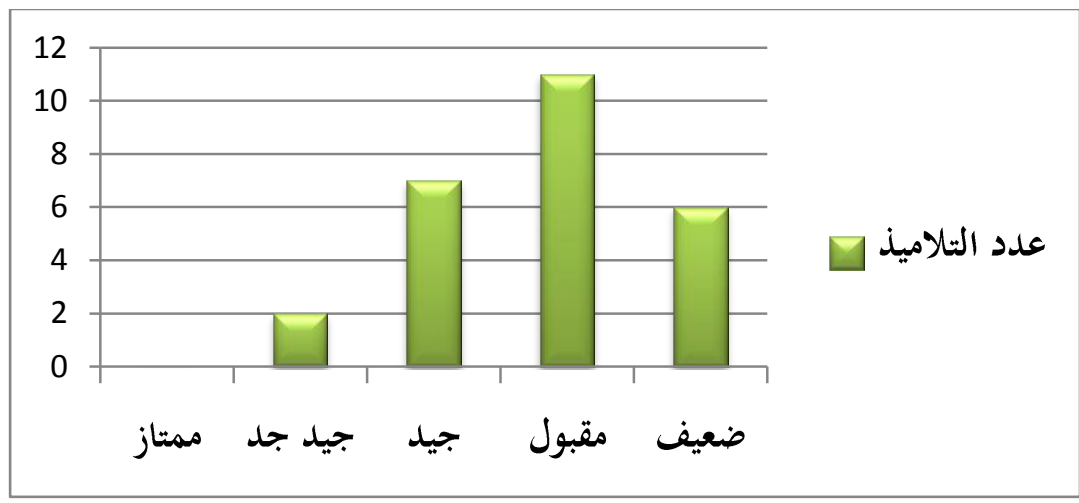

فمن نتائج هذا الاختبار البعدي, ظهر أن التلاميذ نالوا الدرجة المعدلة 66,07 وأما التلاميذ في مستوى ممتاز= 0 وفي مستوى جيد جدا= 2 وفي مستوى جيد= 7 وفي مستوى مقبول= 11 وفي مستوى ضعيف= 6 و من هنا فإن قدرتهم على تعليم المفردات بصفة مقبولة. نتائتج الاختبار القبلي للمجبموعة التجبريبة

\begin{tabular}{|c|c|c|c|}
\hline التقدير & الاختبار القبلي & اسماء التلاميذ & الرقم \\
\hline ضعيف & 56 & أديتيا سفوترا & 1 \\
\hline جيد & 76 & أغيل رندي تري س & 2 \\
\hline ضعيف & 52 & أورا أغوستينيغروم & 3 \\
\hline ضعيف & 42 & دياة رحمة ساري & 4 \\
\hline ضعيف & 48 & أرفيان أنانتا إسكاندار & 5 \\
\hline جيدجدا & 88 & إسراة العزة الزمزمية & 6 \\
\hline مقبول & 68 & خيرة النساء & 7 \\
\hline جيدجدا & 84 & محمد دري فرايوغا & 8 \\
\hline ضعيف & 56 & ماولانا ماندال فوترا & 9 \\
\hline
\end{tabular}




\begin{tabular}{|c|c|c|c|}
\hline ضيعيف & 48 & محمد ديون باغوس ف & 10 \\
\hline جيد & 76 & محمد فردان أناشـار & 11 \\
\hline مقبول & 66 & محمد راحني س & 12 \\
\hline مقبول & 60 & نور ناديفا س أ & 13 \\
\hline ضعيف & 48 & فوترا بايو س م & 14 \\
\hline مقبول & 60 & ريان أفاندي & 15 \\
\hline ضعيف & 44 & ريسا كرنياواي & 16 \\
\hline ضعيف & 42 & ريسكا فاطمة & 17 \\
\hline مقبول & 60 & سافي سادوا & 18 \\
\hline ضعيف & 56 & سفينة عارفة & 19 \\
\hline ضعيف & 56 & سافيتا & 20 \\
\hline ضعيف & 52 & ثانية و أ & 21 \\
\hline مقبول & 60 & سيتي ماريم نعمة ر & 22 \\
\hline جيد & 72 & سوريا فاجارن & 23 \\
\hline ضعيف & 52 & شرفا عند مولايا & 24 \\
\hline ضيعيف & 42 & وينيتا فبريانتي & 25 \\
\hline مقبول & 60 & إماية مرضية & 26 \\
\hline \multicolumn{2}{|c|}{1524} & \multicolumn{2}{|l|}{ العدد } \\
\hline \multicolumn{2}{|c|}{58.61} & \multicolumn{2}{|l|}{ المعدل } \\
\hline
\end{tabular}

نتائج الاختبار القبلي للمجموعة التجبريبة

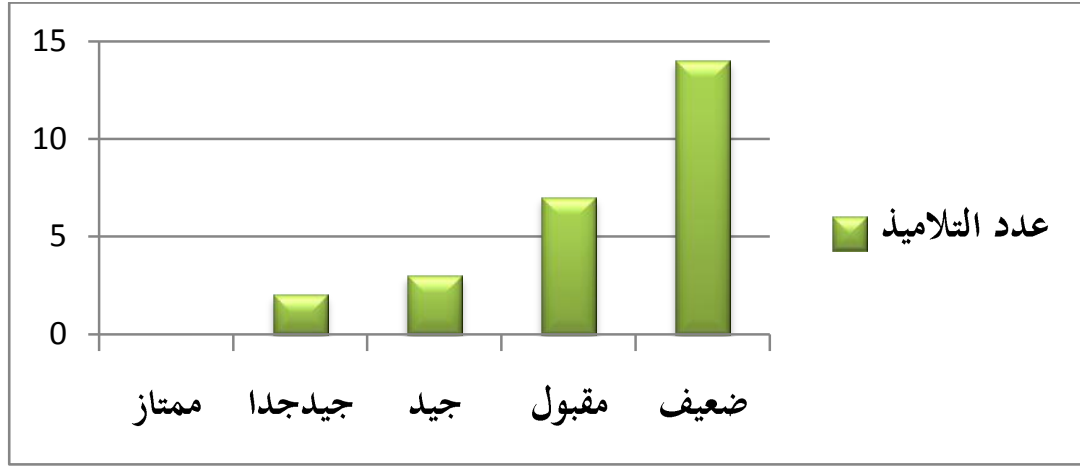

فمن نتائج هذا الاختبار القبلي, ظهر أن التلاميذ نالوا الدرجة المعدلة 58،61 وأما التلاميذ في مستوى ممتاز = 0 وفي مستوى جيد جدا = 2 وفي مستوى جيد = 3 وفي مستوى مقبول = 7 وفي مستوى ضعيف = 14. و من هنا فإن قدرتهم على تعليم المفردات بصفة ضعيفة. نتائج الاختبار البعدي للمجموعة التجريبة

\begin{tabular}{|c|c|c|c|}
\hline التقدير & الاختبار البعدي & اسماء التلاميذ & الرقم \\
\hline جيدجدا & 84 & أديتيا سفوترا & 1 \\
\hline ممتاز & 96 & أغيل رندي تري س & 2 \\
\hline ممتاز & 96 & أورا أغوستينيغروم & 3 \\
\hline ممتاز & 96 & دياة رحمة ساري & 4 \\
\hline جيدجدا & 84 & أرفيان أنانتا إسكاندار & 5 \\
\hline ممتاز & 92 & إسراة العزة الزمزمية & 6 \\
\hline ممتاز & 96 & خيرة النساء & 7 \\
\hline جيدجدا & 84 & محمد دري فرايوغا & 8 \\
\hline
\end{tabular}




\begin{tabular}{|c|c|c|c|}
\hline جيدجدا & 84 & ماولانا ماندال فوترا & 9 \\
\hline جيد & 76 & محمد ديون باغوس ف & 10 \\
\hline جيد & 76 & محمد فردان أناشـار & 11 \\
\hline ممتاز & 92 & محمد راحني س & 12 \\
\hline ممتاز & 96 & نور ناديفا س أ & 13 \\
\hline جيدجدا & 84 & فوترا بايو س م & 14 \\
\hline مقبول & 60 & ريان أفاندي & 15 \\
\hline جيدجدا & 88 & ريسـا كرنياواي & 16 \\
\hline جيدجدا & 84 & ريسكا فاطمة & 17 \\
\hline جيدجدا & 84 & سافي سادوا & 18 \\
\hline جيدجدا & 88 & سفينة عارفة & 19 \\
\hline جيد & 76 & سافيتا & 20 \\
\hline مقبول & 60 & ثانية و أ & 21 \\
\hline جيدجدا & 88 & سيتي ماريم نعمة ر & 22 \\
\hline جيد & 76 & سوريا فاجارن & 23 \\
\hline ممتاز & 92 & شرفا عند مولايا & 24 \\
\hline مقبول & 62 & وينيتا فبريانتي & 25 \\
\hline جيد & 76 & إماية مرضية & 26 \\
\hline \multicolumn{2}{|c|}{2166} & \multicolumn{2}{|l|}{ العدد } \\
\hline \multicolumn{2}{|c|}{83,30} & \multicolumn{2}{|l|}{ المعدل } \\
\hline
\end{tabular}

نتائج الاختبار البعلدي للمتجموعة التجريبة

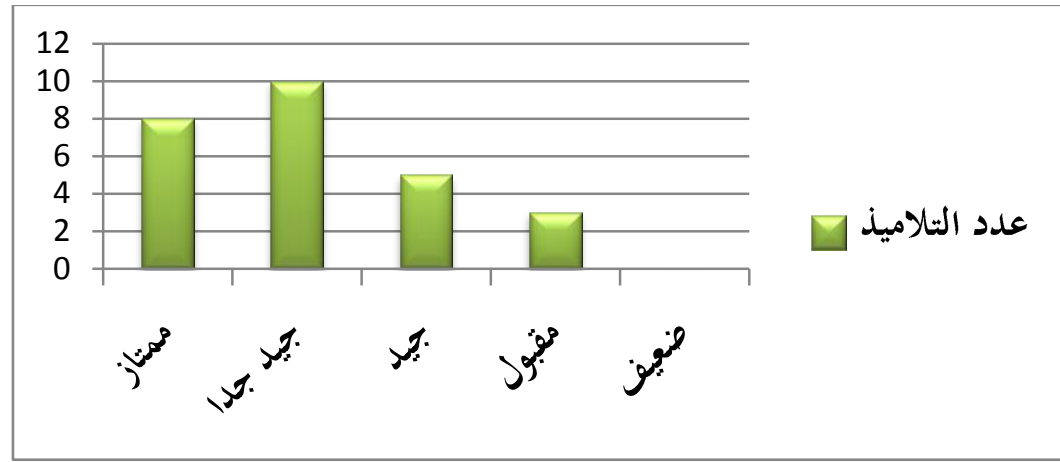

فمن نتائج هذا الاختبار البعدي, ظهر أن التلاميذ نالوا الدرجة المعدلة 83,30 وأما التلاميذ في مستوى ممتاز = 8 وفي مستوى جيد جدا= 10 وفي مستوى جيد = 5 وفي مستوى مقبول = 3 وفي مستوى ضعيف=0. و من هنا فإن قدرتهم على تعليم المفردات بصفة جيدة جدا. مقارنة نتائج الاختبار القبلي والبعدي للمجموعة الضيابطة

\begin{tabular}{|c|c|c|c|c|c|c|}
\hline \multicolumn{2}{|c|}{ الاختبار البعدي } & \multicolumn{2}{|c|}{ الاختبار القبلي } & \multirow{2}{*}{ النتيجة } & \multirow{2}{*}{ المستوى } & \multirow{2}{*}{ الرقم } \\
\hline النسببة المئوية & عدد التلاميذ & النسبـة المئويسة & عدد التلاميذ & & & \\
\hline- & - & - & - & $100-90$ & ممتاز & 1 \\
\hline$\% 7,69$ & 2 & - & - & $89-80$ & جيد جدا & 2 \\
\hline$\% 26,92$ & 7 & $\% 11,53$ & 3 & $79-70$ & جيد & 3 \\
\hline$\% 42,30$ & 11 & $\% 26,92$ & 7 & $69-60$ & مقبول & 4 \\
\hline$\% 23,07$ & 6 & $\% 61,53$ & 16 & $59-0$ & ضعيف & 5 \\
\hline \%100 & 26 & $\% 100$ & 26 & & العد. & \\
\hline
\end{tabular}




\section{المقارنة بين الاختبار القبلي والبعلدي للمجموعة الضابطة}

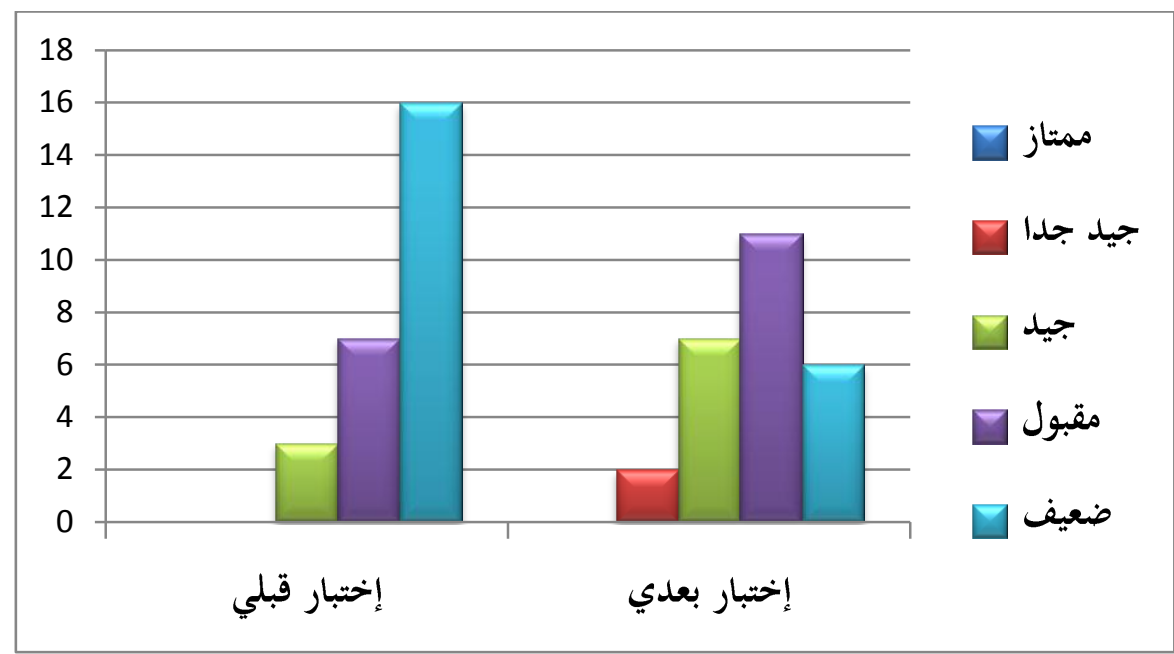

وبالنسبة إلى بيان المقارنة بين الاختبار القبلي و البعدي للمجموعة الضابطة فظهر أن في الاختبار القبلي 61,53\% من التلاميذ في مستوى ضعيف, وفي مستوى مقبول 26,92\%, وفي مستوى جيد 11,53\%. وأما في الاختبار البعدي ظهر أن ضعيف 23,07\%, وفي مستوى مقبول 42,30\%, وفي مستوى جيد 26,92\%, وفي مستوى جيدجدا 7,69\%. وهذا البيان يعني السابق أن نتيجة الاختبار البعدي أكثر من نتيجة الاختبار القبلي.

مقارنة نتائج الاختبار القبلي والبعدي للمدجموعة التجبريبة

\begin{tabular}{|c|c|c|c|c|c|c|}
\hline \multicolumn{2}{|c|}{ الاختبار البعدي } & \multicolumn{2}{|c|}{ الاختبار القبلي } & \multirow{2}{*}{ النتيجة } & \multirow{2}{*}{ المستوى } & \multirow{2}{*}{ لرقم } \\
\hline النسبة المئوية & عدد التلاميذ & النسبية المئوية & عدد التلاميذ & & & \\
\hline$\% 30,76$ & 8 & - & - & $100-90$ & ممتاز & 1 \\
\hline$\% 38,46$ & 10 & $\% 7,69$ & 2 & $89-80$ & جيد جدا & 2 \\
\hline$\% 19,23$ & 5 & $\% 11,53$ & 3 & $79-70$ & جيد & 3 \\
\hline$\% 11,53$ & 3 & $\% 26,92$ & 7 & $69-60$ & مقبول & 4 \\
\hline- & - & $\% 53,84$ & 14 & $59-0$ & ضعيف & 5 \\
\hline$\% 100$ & 26 & $\% 100$ & 26 & & العدد & \\
\hline
\end{tabular}

المقارنة بين الاختبار القبلي والبعلدي للمجبموعة التجبريبة

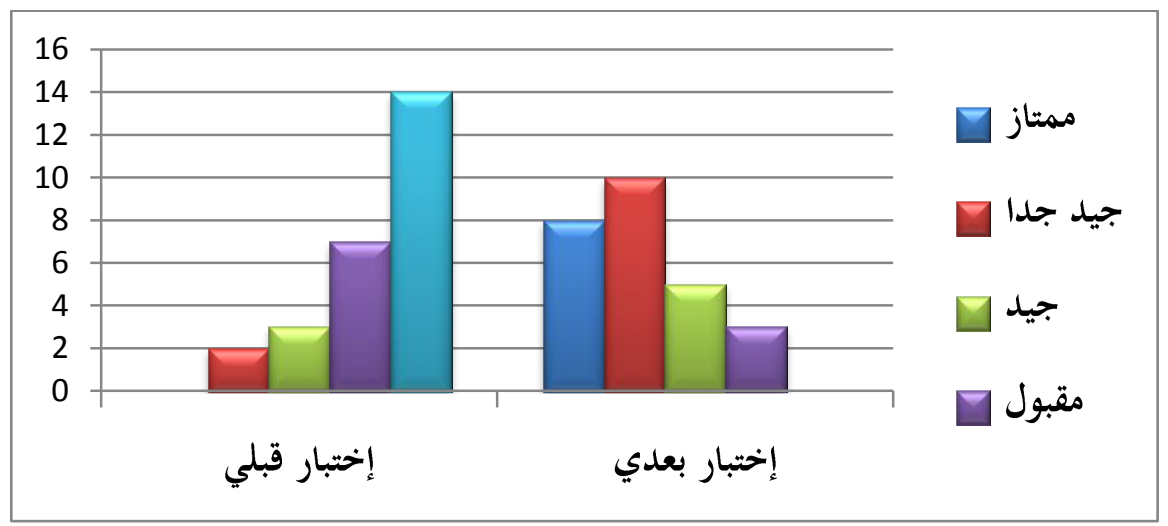


وبالنسبة إلى بيان المقارنة بين الاختبار القبلي و البعدي للمجموعاة التجريبة فظهر أن في الاختبار القبلي 53,84\% من التلاميذ في مستوى ضعيف, وفي مستوى مقبول 26,92\%, وفي مستوى جيد 11,53\% وأما في الاختبار البعدي ظهر أن 11,53\% من التلاميذ في مستوى مقبول, وفي مستوى جيد 19,23, وفي مستوى جيد جدا 38,46\%, وفي مستوى ممتاز 30,76\% . وهذا البيان يعني السابق أن نتيـجة الاختبار البعدي أكثر من نتيجة الاختبار القبلي.

\section{مقارنة نتائج الاختبار البعلدي للمجموعة الضبابطة والتجبيبة}

وبعد الاكمال من عرض بيان نتائج الاختبارين القبلي والبعدي من المجموعتين فينبغي للباحثة أن تعرض بيان مقارنة نتائج الاختبار البعدي بين المجموعاة الظابطة والتجريبة. والمقارنة كما يلي:

\begin{tabular}{|c|c|c|c|c|}
\hline الاختبار البعدي & المجموعة التجريبة & الاختبار البعدي & المجموعة الظابطة & الرقم \\
\hline 84 & أديتيا سفوترا & 76 & أدي فراستيو & 1 \\
\hline 96 & أغيل رندي تري س & 76 & أحمد زيزال مونتلا & 2 \\
\hline 96 & أورا أغوستينيغروم & 76 & دفترا أناندا ساتيا ب & 3 \\
\hline 96 & دياة رحمة ساري & 76 & ديفا عفيفة زهرة & 4 \\
\hline 84 & أرفيان أنانتا إسكاندار & 84 & فبري ألديانشا & 5 \\
\hline 92 & إسراة العزة الزمزمية & 56 & فيرزام دار الفاناني & 6 \\
\hline 96 & خيرة النساء & 88 & جي فيفي فوتري أيوني & 7 \\
\hline 84 & محمد دري فرايوغا & 76 & لينا فورناما دوي & 8 \\
\hline 84 & ماولانا ماندال فوترا & 60 & منبع الهمة أ & 9 \\
\hline 76 & محمد ديون باغوس & 60 & ميغا فراستيوي & 10 \\
\hline 76 & محمد فردان أناشـار & 60 & ميشا عفيفة رحمة & 11 \\
\hline 92 & محمد راحني س & 72 & محمد فابيو جانافارو & 12 \\
\hline 96 & نور ناديفا س أ & 60 & محمد أرجون س & 13 \\
\hline 84 & فوترا بايو س م & 44 & محمدفخراني & 14 \\
\hline 60 & ريان أفاندي & 68 & محمد فيدي ي ف & 15 \\
\hline 88 & ريسـا كرنياواي & 68 & نيها فريهاتين & 16 \\
\hline 84 & ريسكا فاطمة & 66 & نوفا أندرياني & 17 \\
\hline 84 & سافي سادوا & 68 & نور السنتـا أ & 18 \\
\hline 88 & سفينة عارفة & 56 & ريدا يوليا تريسناواتي & 19 \\
\hline 76 & سافيتا & 60 & رسما أدي ف & 20 \\
\hline 60 & ثانية و أ & 76 & رسفاندي أغوس ك & 21 \\
\hline 88 & سيتي ماريم نعمة ر & 56 & رزكي فورنومو & 22 \\
\hline 76 & سوريا فاجارن & 56 & سافيرا إيكا أ & 23 \\
\hline 92 & شرفا عند مولايا & 52 & سفتيان دوي فرناما ف & 24 \\
\hline 62 & وينيتا فبريانتي & 60 & سيلفيا أ & 25 \\
\hline 76 & إماية مرضية & 68 & فانيا ليل رمضاني & 26 \\
\hline 2166 & المجموع & 1718 & المجموع & $\mathrm{N}$ \\
\hline
\end{tabular}

ظهر من الجدول السابق أن نتائج الاختبار البعدي للمجموعة التجريبة = 2166 أكبر من نتائج الاختبار البعدي للمجموعة الضيابطة = 1718. 


\section{نتائج عدد الإنحراف وعلدد الإنحراف المربع من المجموعتين}

وبعد مقارنة نتائج الاختبار البعدي بين المجموعـة الضابطة والتجريبة، فشرحت الباحثة بتقويم

نتائج عدد الإنحراف وعدد الإنحراف المربع من المجموعتين وهي كما جدول يلي:

\begin{tabular}{|c|c|c|c|c|c|c|c|c|}
\hline \multicolumn{4}{|c|}{ المجموعة الضابطة } & \multicolumn{4}{|c|}{ المجموعة التجريبة } & \multirow{2}{*}{ الرقم } \\
\hline$y^{2}$ & $\mathrm{Y}$ & $y_{2}$ & $y_{1}$ & $x^{2}$ & $x$ & $x_{2}$ & $x_{1}$ & \\
\hline 0 & 0 & 76 & 76 & 784 & 28 & 84 & 56 & 1 \\
\hline 400 & 20 & 76 & 56 & 400 & 20 & 96 & 76 & 2 \\
\hline 400 & 20 & 76 & 56 & 1936 & 44 & 96 & 52 & 3 \\
\hline 256 & 16 & 76 & 60 & 2916 & 54 & 96 & 42 & 4 \\
\hline 1600 & 40 & 84 & 44 & 1296 & 36 & 84 & 48 & 5 \\
\hline 144 & 12 & 56 & 44 & 16 & 4 & 92 & 88 & 6 \\
\hline 144 & 12 & 88 & 76 & 784 & 28 & 96 & 68 & 7 \\
\hline 16 & 4 & 76 & 72 & 0 & 0 & 84 & 84 & 8 \\
\hline 144 & 12 & 60 & 48 & 784 & 28 & 84 & 56 & 9 \\
\hline 324 & 18 & 60 & 42 & 784 & 28 & 76 & 48 & 10 \\
\hline 256 & 16 & 60 & 44 & 0 & 0 & 76 & 76 & 11 \\
\hline 256 & 16 & 72 & 56 & 676 & 26 & 92 & 66 & 12 \\
\hline 16 & 4 & 60 & 56 & 1296 & 36 & 96 & 60 & 13 \\
\hline 4 & 2 & 44 & 42 & 1296 & 36 & 84 & 48 & 14 \\
\hline 144 & 12 & 68 & 56 & 0 & 0 & 60 & 60 & 15 \\
\hline 0 & 0 & 68 & 68 & 1936 & 44 & 88 & 44 & 16 \\
\hline 196 & 14 & 66 & 52 & 1764 & 42 & 84 & 42 & 17 \\
\hline 64 & 8 & 68 & 60 & 576 & 24 & 84 & 60 & 18 \\
\hline 144 & 12 & 56 & 44 & 1024 & 32 & 88 & 56 & 19 \\
\hline 0 & 0 & 60 & 60 & 400 & 20 & 76 & 56 & 20 \\
\hline 156 & 16 & 76 & 60 & 64 & 8 & 60 & 52 & 21 \\
\hline 64 & 8 & 56 & 48 & 784 & 28 & 88 & 60 & 22 \\
\hline 144 & 12 & 56 & 44 & 16 & 4 & 76 & 72 & 23 \\
\hline 64 & 8 & 52 & 44 & 1600 & 40 & 92 & 52 & 24 \\
\hline 0 & 0 & 60 & 60 & 400 & 20 & 62 & 42 & 25 \\
\hline 0 & 0 & 68 & 68 & 256 & 16 & 76 & 60 & 26 \\
\hline 4936 & 282 & 1718 & 1436 & 21788 & 646 & 2166 & 1524 & المجموع \\
\hline$\sum \boldsymbol{y}^{2}$ & $\sum y$ & & & $\sum x^{2}$ & $\sum x$ & & & \\
\hline
\end{tabular}

وبعد توضيح الجدول السابق، تخلص الباحثة بعض النتائج الآتية عدد الإنحراف، ومجموعة عدد الإنحراف المربع من المجموعة الظابطة والمجموعاة التجريبة، وهي كما يلي:

مجموع عدد الإنحراف وعدد الإنحراف المربع من المجموعتين

\begin{tabular}{|c|c|c|c|}
\hline \multicolumn{2}{|c|}{ المجموع الضابطة } & \multicolumn{2}{|c|}{ المجموع التجريبة } \\
\hline مجموع عدد الإنحراف & مجموع عدد الإنحراف & مجموع عدد الإنحراف & مجموع عدد الإنحراف \\
\hline المربع ( & $\left(\sum \boldsymbol{y}\right)$ & المربع ( & $\left(\sum \boldsymbol{x}\right)$ \\
\hline 4936 & 282 & 21788 & 646 \\
\hline
\end{tabular}


وجدت الباحثة أن نيجة t الإحصائي = 4 t-29 ثم قامت الباحثة بتعيين t-table بحثت الباحثة نتيجتـه في القائمة الحرية (degree of freedom) من t-table فوجد أن نتيجته 50 في المستوى المعنى 1\% = 2،42 و في المستوى المعنى 5\% = 68،2، وهذا تقرير"ت (t)":

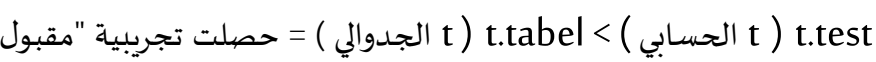

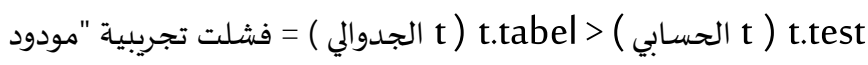

لأن نتيجة t الإحصائي = 29،4 أكبر من نتيجة المستوى المعنوي 1\% = 42،2 وكذالك أكبر من نتيجة المستوى المعنوي 5\% = 68،2 وذلك بمعنى أن H مقبول يعنى أن فروض هذا البحث مقبولة. وخلاصتها أن باستخدام لعبة المونوبولي في ترقية كفاءة المفردات فعالية. استخدام لعبة المونوبولي في ترقية كفاءة المفردات في الفصل الواحد أ بمدرسة هداية المبتدئين المتوسطة الإسلامية بمالانج فهي الوسيلة التعليمة تستخدمت الباحثة لترقية كفاءة المفردات التلاميذ. هذه الوسيلة تملك الفوائد الكثيرة لتلاميذ في الفصل أ منها: 1) باستخدام لعبة المونوبولي، التلاميذ يشعرون بالحماسة والسعادة عند عملية التعلم في الفصل، 2) تعليم المفردات باستخدام لعبة المونوبولي تستطيع أن يسهل التلاميذ لترقية كفاءة المفردات، 3) لعبة المونوبولي أن تدفع التلاميذ للتعلم بالنشيط، 4) لعباة المونوبولي تستطيع إزالة الملل عند عملية العلم وتستطيع أن تأكيد فهم التلاميذ على المواد التعليمياة. كما قال عبد الوهاب راشيد وأمي محمودة في كتابهما فهي: 1) يجعل التعلم أكثر جذبا حتى يمكن ان تعزز الدافعة والإهتمام للتعلم، 2)تقديم للتلاميذ أسـاسا ماديا للإدراك الحاسي، ومن ثم فهي تقلل من استخدام التلاميذ الألفاظ لايفهمون لها معنى، 3) أن يكون مواد التعليمية أكثر وضوح معنها، حتى المفهوم للمعام فضلا عن السماح المتعلم على إتقان أغراض التدريس جيدا، 4) تختلف قواعد التعلم، نطق المدرس لا إتصال اللفظي فقط. لا يميل الطلبة، لا يتعب للمعلم، 5) أكثر الأنشطة للتلاميذ لأنه لا يسمع إلى شرح المعلم وحده ولكن الأنشطة الأخرى مثل نفذت لمراقبة وتنفيذ والتظاهر، وغيرهم (Rosyidi and Machmudah n.d) 1) تثير اهتمام التلاميذ كثيرا، 2) توفير وتحسين اختلافات التعلم، 3) تجعل ما يتعلمونه باقي الأثر، 4) تقدم خبرات واقعية تدعو التلاميذ إلى النشاط الذاتي، 5) تنمي في التلاميذ استمرار في الفكر، كما هو الحال عند استخدام الصور المتحركة والتمثيليات والرحلات، 6) سيفهم التلاميذ المواد التعليمية بمنهجية التدريس(Rosyidi and Machmudah n.d.). 


\section{خاتمة}

أدوات لعبة المونوبولي هي: (1) البيذق لينوب اللاعب؛ (2) النردان، وكل النرد له ستة وجوه؛ (3)

لوحة اللعبة بالخانة؛ (4) فلوس اللعبة؛ (5) بطاقة سؤال أ و ب. أما المواد الدراسي في لعبة المونوبولي فهي: موضوع "بيتي" في كتاب التعليم. أما نظام اللعبة المونوبولي فهي: (1) تقسم التلاميذ إلى الفرقات (وفقت تعداد التلاميذ في الفصل)؛ (2) يعطي لوحة اللعبة المونوبولي والفلوس والبيذق والنرد إلى كل الفرقة؛ (3) يرمي النرد من كل الفرقة؛ (4) يتحرك البيذق حسبما الرقم المكتوب في النرد؛ (5) تجب على التلاميذ أن تجيب الأسئلة في كل الخانة؛ (6) إذا لا تستطيع التلاميذ أن تجيب الأسئلة تقول التلاميذ الكلمة "يكفي" وتنتظر العقبة التالية؛ (7) والتلاميذ يحصلون أكثر الفلوس هو الفائزة. فعالية استخدام لعبة المونوبولي في ترقية كفاءة المفردات بمدرسة هداية المبتدئين المتوسطة الإسلامية بمالانج: حصلت عليها التلاميذ في الاختبار القبلي والبعدي، فيتضح أن قدرة التلاميذ في استيعاب المفردات من جهة مفهوم معناها مرتفعة بعد تعلمها باستخدام المونوبولي. وجدت الباحثة أن نتيجاة t الإحصائي = 29،4 أكبر من نتيجة المستوى المعنوي 1\% هي 42،2 وكذلك أكبر من نتيجة المستوى المعنى 5\% = 68،2. وخلاصته لأن 0 H مردود، $H_{1}$ م مقبول أي فروض هذا البحث مقبولة. وخلاصتها أن استخدام لعباة المونوبولي في ترقية كفاءة المفردات فعالية.

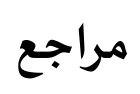

Arikunto, Suharsini. 2010. Prosedur Penelitian: Suatu Pendekatan Praktik. Jakarta: Rineka Cipta.

Effendi, Ahmad Fuad. 2005. Metodologi Pengajaran Bahasa Arab. Malang: Misykat.

Emzir. 2009. Metodologi Penelitian Kuantitatif Dan Kualitatif. Jakarta: Rajawali Pers.

Hamid, Abdul and dkk. 2008. Pembelajaran Bahasa Arab (Pendekatan, Metode, Strategi, Materi, Dan Media). Malang: UIN Malang Press.

Rosyidi, Abdul Wahab and Umi Machmudah. n.d. Aktif Learning Dalam Pembelajaran Bahasa Arab. Malang: UIN Malang Press.

Sugiyono. 2011. Metode Penelitian Kuantitatif Kualitatif Dan RED. Bandung: Alfabeta.

Syamsuddin, AR and Vismaia S. Damianti. 2006. Metode Penelitian Bahasa. Bandung: Remaja Rosdakarya.

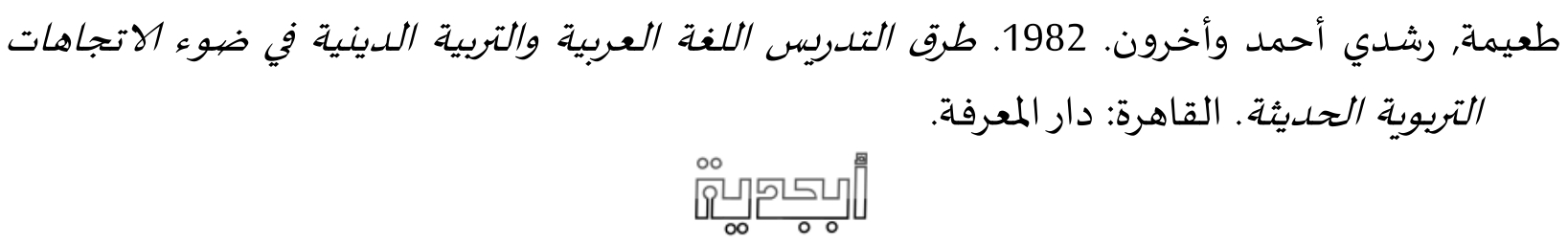

